The two annual reports have provided the first detailed analysis of transfusion errors in the United Kingdom, an approach already recommended in the United States. ${ }^{10}$ Following defined procedures for blood handling ${ }^{11}$ and regular staff training are crucial; bedside $\mathrm{ABO}$ grouping has a high error rate ${ }^{12}$ and is not recommended by SHOT, although it is mandated in France. Medical and nursing staff must be aware of the possibility of $\mathrm{ABO}$ incompatibility or bacterial infection in a shocked recipient of transfusion, while errors in identification will be minimised by procedural training for porters and phlebotomists and by forthcoming guidelines for blood handling and administration from the British Committee for Standards in Haematology. Infections transmitted by transfusion were relatively rare, a finding consistent with the calculated low residual viral risk, ${ }^{13}$ now overtaken by the frequency of bacterial contamination of platelet concentrates. ${ }^{14}$ SHOT data provide mixed messages: the risk:benefit ratio of appropriate transfusion is high compared with other risks in life, ${ }^{15}$ but safety can still be improved. The United Kingdom lacks a unified body to take an overview of all aspects of blood safety, sometimes making it difficult to practise "aligning effort with risks." ${ }^{16}$ Technological advances such as viral genomic detection and inactivation may be mandated by regulatory authorities, but prevention of transfusion error requires local managerial commitment, "process re-engineering," ${ }^{17}$ and an active hospital transfusion committee. Hopefully the concept of clinical governance will focus resources in this important area.

Contributors: LMW, EML, PS, and JAJB took part in the establishment of the SHOT scheme, design of the questionnaire, analysis of data, and compilation of the report. SL, HC, and KS took part in design of the questionnaire, analysis of data, and compilation of the report. DBLMcC took part in the establishment of the SHOT scheme, analysis of data, and compilation of the report. LMW, HC, and EML are the guarantors.

Funding: UK Transfusion Services, Republic of Ireland Transfusion Service, British Society for Haematology, British Transfusion Society.

Competing interests: None declared.

1 Sazama K. Reports of 355 transfusion-associated deaths: 1976 through 1985. Transfusion 1990;30:583-90.

McClelland DBL, Phillips P. Errors in blood transfusion in Britain: survey of hospital haematology departments. BMJ 1994;308:1205-6.

3 Williamson LM, Heptonstall J, Soldan K. A SHOT in the arm for safer blood transfusion. BMJ 1996;313:1221-2.

4 BCSH Blood Transfusion Task Force. Guidelines for pre-transfusion compatibility procedures in blood transfusion laboratories. Transfusion Medicine 1996;6:273-83.

5 Shiba MK, Tadokoron K, Sawanobori M, Nakajima K, Suzuki K, Juji T Activation of the contact system by filtration of platelet concentrates with a negatively charged white cell-removal filter and measurement of venous blood bradykinin level in patients who received the filtered platelets. blood bradykinin level in pation 1997;37:457-62.
Transfusion

6 Williamson LM, Lowe S, Love EM, Cohen H, Soldan K, McClelland DBL, et al. SHOT annual report 1996-1997. Manchester: SHOT Office, Manchester Blood Centre, 1998.

7 Williamson LM, Lowe S, Love EM, Cohen H, Soldan K, McClelland DBI, et al. SHOT annual report 1997-1998. Manchester: SHOT Office, Manchester Blood Centre, 1999.

8 NHS Executive. Better blood transfusion. London: NHS Executive, 1999. (Circular HSC 1998/99.)

9 Centre National d'Hémovigilance. L'hémovigilance actualites et dossiers: lettre dinformation de l'Agence Française du sang en collaboration avec le Centre National d'Hémovigilance. Avril 1995 and Mars 1996. Paris: Agence Francaise du Sang, 1999.

10 Kaplan HS, Battles JB, Van der Schaaf TW, Shea CE, Mercer SQ. Identification and classification of the causes of events in transfusion medicine. Transfusion 1998;38:1071-81.

11 Lumadue JA, Boyd JS, Ness PM. Adherence to a strict specimen-labelling policy decreases the incidence of erroneous blood grouping of blood bank specimens. Transfusion 1997;37:1169-72.

12 Ingrand P, Surer-Pierres N, Houssay D, Salmi LR. Reliability of the pretransfusion bedside compatibility test: association with transfusion practice and training. Transfusion 1998;98:1030-6.

13 Schreiber GB, Busch MP, Kleinman SH, Korelitz JJ. The risk of transfusion-transmitted viral infections. $N$ Engl J Med 1996;334:1685-90. 14 Blajchman MA, Ali AM, Richardson HL. Bacterial contamination of cellular blood components. Vox Sang 1994;67:25-34.

15 Calman KC. Cancer: science and society and the communication of risk. BMJ 1996:313;799-802

16 AuBuchon JP, Kruskall MS. Transfusion safety; realigning efforts with risks. Transfusion 1997:37:1211-6.

17 McClelland DBL. Treating a sick process. Transfusion 1998;38:999-1103. (Accepted 19 April 1999)

\title{
Cost minimisation analysis of provision of oxygen at home: are the Drug Tariff guidelines cost effective?
}

\author{
Liam G Heaney, Denise McAllister, Joseph MacMahon
}

\begin{abstract}
Objectives To determine the level of oxygen cylinder use at which it becomes more cost effective to provide oxygen by concentrator at home in Northern Ireland, and to examine potential cost savings if cylinder use above this level had been replaced by concentrator in 1996.

Design Cost minimisation analysis.

Setting Area health boards in Northern Ireland. Main outcome measures Cost effective cut off point for switch to provision of oxygen from cylinder to concentrator. Potential maximum and minimum savings in Northern Ireland (sensitivity analysis) owing to switch to more cost effective strategy on the basis of provision of cylinders in 1996.

Results In Northern Ireland it is currently cost effective to provide oxygen by concentrator when the
\end{abstract}

patient is using three or more cylinders per month independent of the duration of the prescription. More widespread use of concentrators at this level of provision is likely to lead to a cost saving. Conclusions The Drug Tariff prescribing guidelines, advocating that provision of oxygen by concentrator becomes cheaper when 21 cylinders are being used per month-are currently inaccurate in Northern Ireland. Regional health authorities should review their current arrangements for provision of oxygen at home and perform a cost analysis to determine at what level it becomes more cost effective to provide oxygen by concentrator.

\section{Introduction}

In the United Kingdom, the provision of oxygen at home can be prescribed either in cylinders (capacity of
Department of Respiratory Medicine, Belfast City Hospital, Belfast BT9 7AB Liam G Heaney, senior registrar

Joseph MacMahon, consultant physician School of Public Policy and Law, University of Ulster, Jordanstown, Belfas Denise McAllister, professor

Correspondence to: Dr Heaney LiamHeaney@ ukgateway.net

BMJ 1999;319:19-23 
1360 litres) or by concentrator (oxygen extracted from air). Oxygen is prescribed either for treating symptoms or as long term oxygen therapy, when it is used to prolong survival in patients with hypoxaemic respiratory failure. ${ }^{12}$ For patients prescribed oxygen, it is more practical and cost effective to provide a concentrator if a large number of cylinders are used per month. The Drug Tariff prescribing guidelines and the Monthly Index of Medical Specialities advocate a change from cylinders to concentrator when monthly usage exceeds 21 cylinders, ${ }^{3}$ a figure reiterated in a recent review of provision of oxygen at home. ${ }^{4}$

We used economic appraisal to determine the level of cylinder use at which it becomes more cost effective to provide oxygen by concentrator at home in Northern Ireland, and to examine the potential cost savings if cylinder use above this level had been replaced by concentrator in 1996 .

\section{Subjects and methods}

Economic evaluation is concerned with comparing the consequences of healthcare interventions with their costs. The four main types of economic evaluation all deal with costs but differ in the way the consequences of an intervention are measured and valued. ${ }^{5}$ As there was no reason to presume that medical effectiveness was altered between the two modes of provision of oxygen, we chose cost minimisation analysis. This form of cost effectiveness analysis is used when the consequences of the alternatives are deemed to be equivalent. ${ }^{5}$ In this context, we defined the more cost effective intervention by cost alone.

\section{Costing methodology}

We considered the costs of provision of oxygen only. We excluded other costs such as drugs, attendances to a doctor, and hospital admission, as there was no reason to presume they would differ between modes of provision. We identified two categories of cost for each type of provision: fixed costs, which are incurred independent of use - for example, installation cost and variable costs, which are dependent on use such as electricity costs. Costs were not discounted as the analytic horizon was 1 year.

The provision of concentrators is funded regionally and not from the prescribing budgets of fundholders or regional health boards. Concentrators are installed and serviced by a single contract holder. Each concentrator has a meter to measure use, and the running costs can be reclaimed by the user. The back-up cylinder is provided by the contract holder at an agreed rate as part of the contract.

Table 1 shows the individual component costs for provision of oxygen by concentrator and cylinder. The ingredient cost of a single delivered oxygen cylinder represents $15 \%$ of the total cost. Both modes of provision are exempt from value added tax.

As fixed costs do not vary, the level of oxygen usage at which it became cost effective to change delivery mode was dependent on variable costs. In effect, the duration of the oxygen prescription and oxygen usage per day (both flow rate and duration of use) were the key determinants. We performed costings for two hypothetical but not atypical clinical scenarios to illustrate the costing methodology and to show how
Table 1 Individual fixed and variable costs in provision of oxygen by concentrator and cylinder at current costs

\begin{tabular}{lc} 
Costs & Rate (£) \\
\hline Concentrator & \\
\hline Fixed: & 44.85 \\
\hline Installation & 3.14 \\
\hline Back-up cylinder & \\
\hline Variable: & 15.89 \\
\hline Rental (per month) & 16.97 \\
\hline Servicing (per quarter) & 0.07 \\
\hline$\quad$ Electricity (per hour) & \\
\hline Cylinder (1360 litres) & \\
\hline Fixed: & 9.90 \\
\hline Service installation & 8.87 \\
\hline Service withdrawal & \\
\hline Variable: & 6.98 \\
\hline Ingredient & 8.87 \\
\hline Dispensing fee & \\
\hline Delivery allowance (miles) & 9.11 \\
\hline$\quad 1-6$ & 16.66 \\
\hline $7-10$ & 18.76 \\
\hline$\quad 11-20$ & 1.93 \\
\hline Flow head rental (per month)
\end{tabular}

${ }^{*}$ Per prescription for each multiple of three items.

Table 2 Fixed and variable costs for 5 hours' oxygen usage per day for 1 month at a flow rate of $2 \mathrm{l} / \mathrm{min}$ for both concentrator and cylinder

\begin{tabular}{lc} 
Costs & Rate (£) \\
\hline Concentrator & \\
\hline Fixed: & 44.85 \\
\hline Installation & 3.14 \\
\hline Back-up cylinder & \\
\hline Variable: & 15.89 \\
\hline Rental & 10.85 \\
\hline Electricity & 74.73 \\
\hline Total cost & \\
\hline Cylinder (1360 litres) & 9.90 \\
\hline Fixed: & 8.87 \\
\hline Service installation & \\
\hline Service withdrawal & 97.72 \\
\hline Variable: & 44.35 \\
\hline Ingredient & 45.55 \\
\hline Dispensing fee & 1.93 \\
\hline Delivery allowance & 208.32 \\
\hline Flow head rental &
\end{tabular}

prescription duration and daily usage affected total cost. We undertook threshold analysis to indicate the values of key variables that would justify revision of prescribing guidelines. For all costings we assumed there were no concentrator breakdowns (an unusual event) and that all deliveries, comprising three cylinders per delivery, were within 6 miles.

Individual concentrator prescriptions are issued from a regional department but cylinder prescriptions are not collated centrally. The only data available were the total ingredient cost and total number of prescriptions in Northern Ireland. The cost of this service varies substantially depending on individual prescription, frequency of deliveries, and distance delivered, and thus it was impossible to determine the actual cost of provision of oxygen. We used sensitivity analysis to provide a range of estimates on the basis of the assumptions about the values that particular variables 
were likely to take, and we used this to give an estimate of the potential savings.

\section{Results}

\section{Scenario 1}

A patient with terminal lung cancer receives palliation from oxygen, which was prescribed for 1 month (31 days) at a flow rate of $2 \mathrm{l} / \mathrm{min}$ for 5 hours per day (14 cylinders over 1 month). After 1 month the patient dies.

Table 2 shows the costs associated with this scenario. At this usage a concentrator is a more cost effective option than cylinders. As usage falls the total costs for each mode of provision approximate, but it would require a reduction in cylinder usage to three for the month (flow rate $2 \mathrm{l} / \mathrm{min}$ ) before the concentrator became more expensive $£ 66.26$ (\$106.02) v $£ 59.62$ (\$95.39)). Using four cylinders for the month at $2 \mathrm{l} / \mathrm{min}$ flow rate, the cylinder would cost $£ 84.58$ (\$135.33) whereas the concentrator would cost $£ 67.05$ (\$107.28). Thus three cylinders used for 1 month at a flow rate of $2 \mathrm{l} / \mathrm{min}$ represent the cost effective cut off point beyond which the provision of oxygen will always be cheaper by concentrator.

\section{Scenario 2}

A patient with chronic obstructive pulmonary disease with a resting arterial oxygen pressure of $8.0 \mathrm{kPa}$ on room air finds oxygen usage at a flow rate of $2 \mathrm{l} / \mathrm{min}$ during and after moderate exertion useful. Average use is for 15 minutes six times per day (approximately one cylinder per week). After 2 years he dies suddenly from a myocardial infarction.

Table 3 shows the costs associated with this scenario. With this amount of use a concentrator is more cost effective than cylinders. Again, as usage falls the total costs for each mode of provision approximate, but it would require a reduction in oxygen usage to four cylinders every 3 months over the 2 years before the concentrator became more expensive than cylinder provision (£573.53 (\$917.65) v $£ 486.23$

Table 3 Fixed and variable costs for 90 minutes' oxygen usage per day for 2 years at a flow rate of $2 \mathrm{l} / \mathrm{min}$ for both concentrator and cylinder

\begin{tabular}{|c|c|}
\hline Costs & Rate $(£)$ \\
\hline \multicolumn{2}{|l|}{ Concentrator } \\
\hline \multicolumn{2}{|l|}{ Fixed: } \\
\hline Installation & 44.85 \\
\hline Back-up cylinder & 3.14 \\
\hline \multicolumn{2}{|l|}{ Variable: } \\
\hline Rental & 381.36 \\
\hline Servicing & 118.79 \\
\hline Electricity & 76.65 \\
\hline Total cost & 624.79 \\
\hline \multicolumn{2}{|l|}{ Cylinder (1360 litres) } \\
\hline \multicolumn{2}{|l|}{ Fixed: } \\
\hline Service installation & 9.90 \\
\hline Service withdrawal & 8.87 \\
\hline \multicolumn{2}{|l|}{ Variable: } \\
\hline Ingredient & 677.06 \\
\hline Dispensing fee & 292.71 \\
\hline Delivery allowance & 300.63 \\
\hline Flow head rental & 46.32 \\
\hline Total cost & 1335.49 \\
\hline
\end{tabular}

(\$777.97)). The cost of provision of five cylinders every 3 months is $£ 596.01$ (\$953.62) and similar concentrator usage would cost $£ 579.87$ (\$927.79). Thus, with oxygen usage over a longer period, cylinder usage becomes more expensive and the cost effective cut off point relates to a smaller number of cylinders used per month, indicating the importance of duration of prescription.

If the duration of prescription is unknown (which is generally the case at prescription issue) it is still possible to determine a cost effective cut off point on the basis of oxygen usage per month. The cut off point for provision of two cylinders per month at a flow rate of $2 \mathrm{l} / \mathrm{min}$ is 6 months (concentrator $£ 186.81$ (\$298.90) (including 6 month service as provision is ongoing) $v$ cylinder $£ 186.03$ (\$297.65)) since again beyond this it is always cheaper to provide equivalent oxygen usage by concentrator.

This cut off point for total cylinder usage is also dependent on flow rate, as at lower flow rates and similar cylinder usage per month the running costs of the concentrator for the same provision of oxygen rises. Thus, given the usage of two cylinders per month at a flow rate of $1 \mathrm{l} / \mathrm{min}$ the cost effective cut off point is 12 months (concentrator £344.63 (\$551.41) v cylinder $£ 353.29$ (\$565.26)). In annual terms, a concentrator is always cheaper if more than 22 cylinders are being consumed per year (annual cost of 22 cylinders or concentrator equivalent: concentrator £341.46 (\$546.34) v cylinder £339.33 (\$542.93)).

We conclude that if more than three cylinders per month are being used, independent of flow rate or duration of prescription, it is always cheaper to prescribe a concentrator. If the duration of prescription is likely to be 12 months or longer it is always cheaper to prescribe a concentrator when two or more cylinders are being used per month whatever the flow rate.

\section{Potential cost savings in Northern Ireland}

Table 4 shows the total ingredient cost and number of prescriptions for provision of oxygen at home in Northern Ireland in 1996. No system collates individual prescriptions, thus cylinder provision per patient is unknown. At one extreme, 1384 patients could have each received 22 cylinders and 1543 patients could have each received 24 cylinders per year (option 1); at the other extreme, if some patients were receiving long term oxygen therapy (defined as $2 \mathrm{l} / \mathrm{min}$ for 15 hours per day) then hypothetically 2793 patients could have each received one cylinder per year and 134 patients could have each received long term oxygen therapy (option 2). Although both these options are unlikely, they allow determination of the range of potential cost savings. On the basis of these costings (annual efficiency cut off point of 22 cylinders per year), option 1 represents the most efficient distribution of oxygen at home in Northern Ireland in 1996 given the total cylinder usage and number of prescriptions. With this option the potential cost savings would be at their minimum. Option 2 determines the maximum possible cost savings, as it involves transference to the cheapest scenario of distribution of oxygen given the defined levels of usage. Table 5 shows the costs of provision of oxygen at home in 1996, assuming 23 cylinders per patient and using current prices and 
Table 4 Number of patients, total number of oxygen cylinders prescribed in Northern Ireland for 1996, and total ingredient cost at current price

\begin{tabular}{lccc} 
No of patients & $\begin{array}{c}\text { Total No of cylinders } \\
\text { dispensed }\end{array}$ & $\begin{array}{c}\text { Average No (approximately) } \\
\text { of cylinders per patient }\end{array}$ & Total ingredient cost (£) \\
\hline 2927 & 67480 & 23 & 471010 \\
\hline
\end{tabular}

Table 5 Costing of cylinder provision in 1996 (assuming 23 cylinders per patient using current costs) and two alternative provision options on basis of actual cylinder usage and number of prescriptions in 1996. Costs are in $£$

\begin{tabular}{lrrr} 
Costs & 1996 & Option $\mathbf{1}^{*}$ & Option 2† \\
\hline Cylinder & & & \\
\hline Service & 54940 & 25978 & 52425 \\
\hline Ingredient & 471010 & 212527 & 19495 \\
\hline Dispensing fees & 207700 & 98209 & 24774 \\
\hline Delivery allowance & 213320 & 100866 & 25444 \\
\hline Flow head rental & 67789 & 32053 & 5390 \\
\hline Concentrator & & & \\
\hline Installation & 0 & 69203 & 6010 \\
\hline Back-up cylinder & 0 & 4845 & 421 \\
\hline Rental & 0 & 294219 & 25551 \\
\hline Servicing & 0 & 104739 & 9096 \\
\hline Electricity & 0 & 58757 & 51355 \\
\hline Total cost & 1014759 & 1001396 & 219961 \\
\hline Saving & & 13363 & 794798
\end{tabular}

* 1543 patients (each using 24 cylinders of oxygen, flow rate $1 \mathrm{l} / \mathrm{min}$ ) transferring to concentrator, and 1384 patients using 22 cylinders each.

+2793 patients using 1 cylinder for 1 month only, and 134 patients receiving long term oxygen therapy ( 2 1/min for 15 hours per day) by concentrator.

the alternative options. In the case of option 1, patients using 22 cylinders per year would continue to use oxygen in this form (as it is cost effective) but those using 24 cylinders per year would transfer to a concentrator yielding a saving of $£ 13363$ (\$21 381). In option 2, again based on the above costings, the 134 patients receiving long term oxygen therapy by cylinder would be transferred to concentrator, and the remaining patients would continue to use one cylinder per year. The saving would be $£ 794798$ (\$1 271677 ) (78\% of the cost of provision of cylinders in 1996). The actual saving would lie somewhere between these values depending on the individual oxygen prescriptions dispensed.

\section{Discussion}

Our study shows that in Northern Ireland it is currently cost effective to provide oxygen by concentrator when the patient uses three or more cylinders per month, independent of the duration of the prescription. If the period of oxygen usage exceeds 12 months, it is more cost effective to provide oxygen by concentrator when the patient uses two cylinders per month. The current Drug Tariff prescribing guidelines, advocating that provision of oxygen by concentrator becomes cheaper when 21 cylinders are being used per month, are therefore inaccurate in Northern Ireland.

We examined the range of potential savings in Northern Ireland. We showed that current information on cylinder prescription was insufficient as individual oxygen prescriptions, frequency of oxygen usage, and delivery costs for oxygen rather than a crude average and ingredient cost, were crucial in determining the savings (or costs) that could be achieved by more widespread prescription of concentrators. There should be little resistance from general practitioners to prescribing more concentrators as this service is funded centrally, and fundholding practices may make substantial savings. Pharmacists may, however, be disappointed as a move to more concentrators is likely to cause some loss of income.

Concentrators are unobtrusive, reliable, and convenient and can be used in multiple outlets in the home. Patients generally prefer this mode of provision of oxygen, although for some the absence of regular deliveries by the pharmacist may increase feelings of isolation. The alternatives we examined were those available for provision of oxygen in the home in the United Kingdom on NHS prescription. Liquid oxygen is not available on the NHS, and although it is a more flexible source of oxygen at home owing to its portability it can only be obtained if purchased by the patient. The costs of contracts for provision of concentrators are similar throughout the United Kingdom and are equivalent to other European countries.

The major assumptions in our cost analysis were that pharmacists transported three cylinders per delivery and that all deliveries were within 6 miles. The delivery of three cylinders is advocated in the Drug Tariff prescribing guidelines: "GPs are asked to cooperate in an effort to make this part [supply] of the oxygen service more cost effective. If more than one or 2 (cylinders) are regularly required for a particular period, prescribing in multiples of 3 cylinders would reduce savings by reducing the number of journeys." Delivery of three cylinders by pharmacists would seem to be standard practice (personal communication). A pharmacist could deliver more cylinders, which would affect the cost of the service. However, even if six cylinders were provided with each delivery in scenario 2 , it would still be a more expensive option. It is also possible that the delivery service could cost more if one cylinder were delivered on each occasion. The assumption that all cylinders are delivered within a 6 mile radius is almost certainly inaccurate, particularly in rural parts of Northern Ireland. The effect of this assumption was to reduce the cost of provision of cylinders making our conclusions more robust.

The cost of concentrator usage was based on the contract of the current provider. More widespread use of concentrators would have an effect on contract price, which would probably fall, altering the cost effective cut off point to fewer cylinders used per month.

\section{Key messages}

- The current Drug Tariff prescribing guidelines are not cost effective for provision of oxygen at home in Northern Ireland

- Individual prescriptions detailing frequency of usage and delivery costs should be recorded

- A switch to a more cost effective strategy is likely to result in a cost saving

- Regional health authorities should examine current arrangements for provision of oxygen at home and should perform cost analyses 


\section{Conclusion}

Our study identified a level of cylinder usage whereby it becomes cost effective to provide oxygen by concentrator at home in Northern Ireland. A more widespread provision of concentrators is likely to represent a cost saving. We would advocate that regional health authorities review their current arrangements for provision of oxygen at home and perform a cost analysis to determine at what level it becomes more cost effective to provide oxygen by concentrator.

Contributors: LGH had the original idea for the study, retrieved the data, performed the costings, and wrote the paper; he will act as guarantor for the paper. DMcA assisted in performing the costings and contributed to writing the paper

JMacM contributed to data interpretation and writing the paper.

Funding: None

Competing interests: None declared.

1 Medical Research Council Working Party (MRC report). Long term domiciliary oxygen therapy in chronic hypoxic cor pulmonale complicating chronic bronchitis and emphysema. Lancet 1981;i:681-6.

2 Nocturnal Oxygen Therapy Trial Group (NOTT). Continuous or nocturnal oxygen therapy in hypoxaemic chronic obstructive lung disease: a clinical trial. Ann Intern Med 1980;93:391-8.

3 Department of Health. Domiciliary oxygen therapy service. Drug Tariff Part X. London: The Stationery Office, 1996.

Rees PJ. Dudley F. Provision of oxygen at home. BMJ 1998;317:935-8

5 Drummond MF, O' Brien B, Stoddart GL, Torrance GW. Methods for economic evaluation of health care programmes, 2nd ed. Oxford: Oxford Medical, 1997.

(Accepted 26 March 1999)

\title{
Risk of HIV related Kaposi's sarcoma and non-Hodgkin's lymphoma with potent antiretroviral therapy: prospective cohort study
}

\author{
Bruno Ledergerber, Amalio Telenti, Matthias Egger for the Swiss HIV Cohort Study
}

The rate of progression to new AIDS defining events has been reduced considerably since the introduction of potent antiretroviral combination therapy. ${ }^{12}$ It is unclear, however, whether the reduction has been the same for all opportunistic infections and malignancies, or whether the effect has been greater for some conditions than for others. We examined this question in the Swiss HIV Cohort Study, a large community cohort of adults with HIV infection.

\section{Participants, methods, and results}

The study methods are described in detail elsewhere. ${ }^{13}$ The cohort includes the majority of people with advanced HIV infection in Switzerland. Potent antiretroviral combination therapy (triple combinations including at least one protease inhibitor) was gradually introduced from 1995 onwards. By mid-1997, 70\% of patients with a history of CD4 cell counts below $200 \times$ $10^{6} / 1$ were receiving this treatment.

The incidence of all new AIDS conditions fell from 157 events (95\% confidence interval 148 to 166$)$ per 1000 person-years in 1992 to 1994 (before combination therapy) to 35 events (26 to 45 ) in the year from July 1997 to June 1998. We analysed AIDS defining opportunistic and malignant events in separate Cox regression models, treating calendar periods as time dependent covariates and adjusting hazard ratios for transmission group, age, and CD4 cell count at baseline. Analyses were based on 6636 participants and 18498 person-years of follow up.

We found substantial reductions in rates of opportunistic events after the introduction of combination therapy. The figure shows hazard ratios for the common AIDS defining opportunistic infections (50 diagnoses or more), any AIDS defining opportunistic infection (1734 diagnoses), Kaposi's sarcoma (258 diagnoses), and systemic non-Hodgkin's lymphoma (110 diagnoses). The relative hazard for progression to any AIDS defining opportunistic infection was 0.20 (0.15 to 0.27$)$, with little heterogeneity between

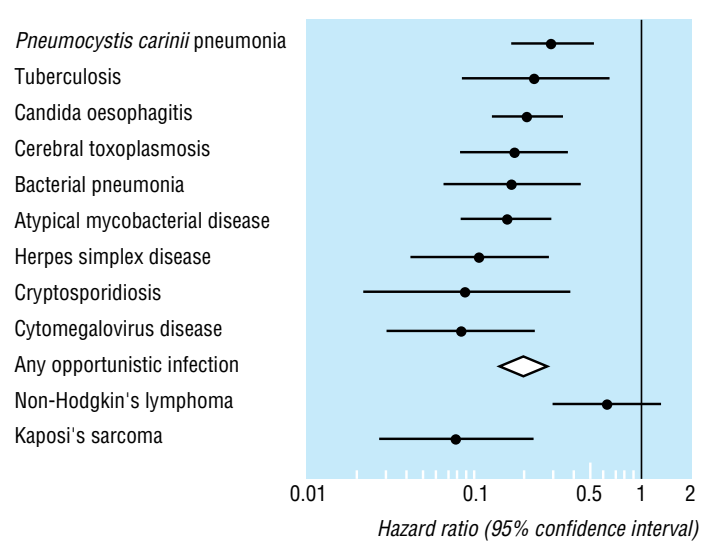

Relative risk (hazard ratio) of AIDS defining opportunistic infections and malignancies, comparing 1992-4 (before introduction of potent antiretroviral combination therapy) with July 1997 to June 1998 (after introduction). Results from Cox regression models adjusted for transmission group, age, and CD4 cell count at baseline

infections. A substantial reduction was also observed for Kaposi's sarcoma (0.08; 0.03 to 0.22). However, no significant trend was evident for non-Hodgkin's lymphoma $(0.61 ; 0.30$ to 1.29$)$, with the difference observed between the two malignancies unlikely to be the product of chance $(\mathrm{P}=0.002)$. Most non-Hodgkin's lymphomas had intermediate or high grade histology and affected extranodal sites. Results for primary lymphoma of the brain were similar to those for nonHodgkin's lymphoma, but the number of cases was small $(n=27)$ and confidence intervals were wide.

\section{Comment}

The incidence of both Kaposi's sarcoma and non-Hodgkin's lymphoma is increased over 100-fold among patients with AIDS, ${ }^{4}$ and these conditions are also more common among patients with other
Division of

Infectious Diseases, Department of

Medicine,

University Hospital Zurich, CH-8091

Zurich, Switzerland Bruno Ledergerber, senior research fellow

Division of

Infectious Diseases,

Department of

Medicine,

University of

Lausanne, $\mathrm{CH}-1011$

Lausanne,

Switzerland

Amalio Telenti,

clinical reader in

infectious diseases

MRC Health

Services Research

Collaboration,

Department of

Social Medicine,

University of

Bristol, Bristol

BS8 2PR

Matthias Egger,

senior lecturer in

epidemiology and

public health medicine

Correspondence to:

Dr Egger

m.egger@bristol.

ac.uk

BMJ 1999;319:23-4

website

extra

Members of the

Swiss HIV Cohort

Study are listed on

the BMJ's website

www.bmj.com 